\title{
Perforation of the duodenum during the retrograde cholangiopancreatography treated without surgery
}

\author{
Akira Tsuji $^{1}$, Daisuke Hashimoto ${ }^{1}$, Tetsu Ozaki ${ }^{2}$, Akira Chikamoto $^{1}$, Toru Beppu $^{1}$, Hideo Baba ${ }^{1 \#}$ \\ ${ }^{1}$ Department of Gastroenterological Surgery, Kumamoto University Graduate School of Medical Sciences, Kumamoto, Japan; \\ \#Corresponding Author: hdobaba@kumamoto-u.ac.jp \\ ${ }^{2}$ Department of Gastroenterology and Hepatology, Kumamoto University Graduate School of Medical Sciences, Kumamoto, Japan
}

Received 17 October 2012; revised 21 November 2012; accepted 30 November 2012

\begin{abstract}
Perforation after endoscopic retrograde cholangiopancreatography (ERCP) is a rare but severe complication. Management of ERCP-associated duodenal perforation remains controversial. Some recommend surgery, while others recommend conservative treatment. We describe the case who developed perforation of the duodenum and gas in the retroperitoneal cavity after ERCP. There was no sign of peritonitis, pancreatitis or sepsis. The patient was treated by conservative therapy without operation, and finally, fully recovered from perforation.
\end{abstract}

Keywords: ERCP; Complication; Perforation; Conservative Therapy

\section{INTRODUCTION}

Endoscopic retrograde cholangiopancreatography (ERCP) is a important invasive technique for revealing and management of a postoperative complication after hepatobiliary surgery [1,2]. The rate of ERCP-related bowel perforation is $0.3 \%$ to $1.0 \%$ [3-6]. The mortality rate in perforated patients is high, from $15 \%$ to $25 \%$ [6,7]. Even now, management of ERCP-associated duodenal perforation remains controversial. Several studies have suggested surgical, endoscopic, radiologic or conservative management $[3,4,8,9]$. We present a case of a perforation of the duodenum during ERCP, recovered by conservative therapy without surgery.

\section{CASE REPORT}

A 77-year-old male underwent a segmental hepatic resection (segments V) for hepatocellular carcinoma in our hospital. Persistent bilious drainage was observed from the percutaneous drain. ERCP with placement of a

\footnotetext{
*The authors declare that they do not have any conflict of interest. The parents of the patient signed a consent for publication of this case report.
}

biliary stent was planned.

The patient had undergone distal gastrectomy for peptic ulcer with Billroth II reconstruction 30 years previously. A long afferent limb of the Billroth II gastroenterostomy made locating the duodenal papilla technically difficult (Figure 1).

Although the catheter was inserted into the common bile duct, placement of sa biliary stent was not success, finally. After the examination, the patient complained upper abdominal pain. Abdominal plain computed tomography (CT) showed gas in the retroperitoneal cavity (Figure 2(a)) and suspected perforation of the duodenum, as the afferent loop, into the retroperitneum (Figure 2(b)). Because there was no evidence of abdominal free air or retroperitoneal fluid collection and physical examination did not showed muscular defense or septic shock, the patient was managed conservatively with gastric aspiration using a nasogastric tube, intravenous fluids and imipenem hydrate/cilastatin sodium administration without surgery. The patient started to drink fluids after 72 hours of gastric aspiration, and was permitted to eat on the 5th day after the ERCP. Two weeks later, enhanced CT showed that gas disappeared and no sign of complication (Figure 3). Finally, the patients fully recovered from perforation.

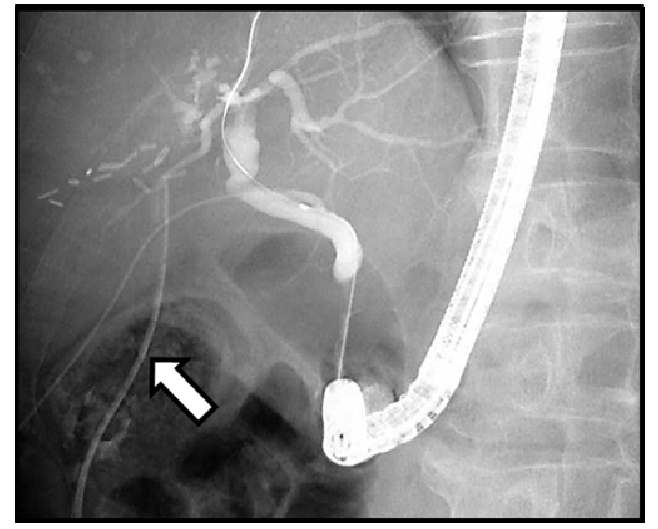

Figure 1. ERCP finding. Endoscope was inserted through the afferent loop. Arrow indicates the percutaneous drain. 


\section{DISCUSSION}

ERCP-related bowel perforations are very rare and unpredictable. Between April 2010 and June 2012, 593 cases of ERCP were performed in our hospital. Among these patients, only the presented case was experienced perforations $(0.17 \%)$. There have been some reports about possible predisposing factors, sphincter of Oddi dysfunction, older age, a dilated bile duct, sphincterotomy, longer duration of the procedure, peripapillary diverticulum and duodenal anatomic abnormalities $[4,10]$. Billroth II gastroenterostomy has been a typical risk factor of the duodenal perforation by ERCP [9]. The afferent jejunal loop was torn by endoscopy during insertion.

Gas in the retroperitoneal cavity disappeared completely and no sign of retroperitoneal fluid collection was observed.

The management of these perforations is variable, with some patients requiring immediate surgery $[3,4]$, and others only conservative management [10]. Kim et al. classified ERCP-related perforations according to mechanism of injury in terms of perforating device [9].

They recommended immediate surgical management to injury by endoscope, whereas surgical or conservative treatment to injury by cannulation catheter, according to intra and retroperitoneal dirty fluid collection findings.
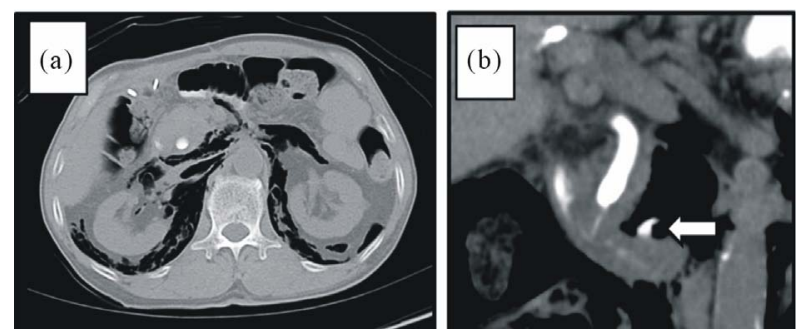

Figure 2. Plain CT scanned immediate after the ERCP. Gas in the retroperitoneal cavity (a) and suspected perforation of the duodenum, as the afferent loop, into the retroperitneum (b) were observed.

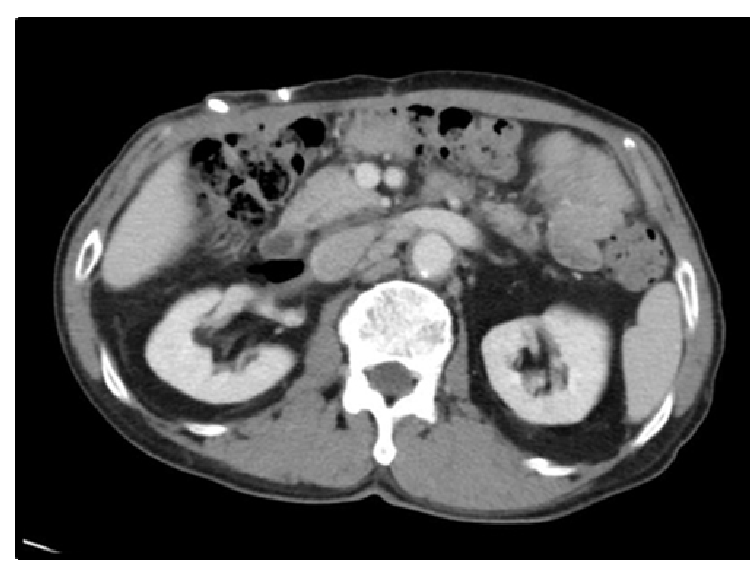

Figure 3. Enhanced CT canned 2 weeks after the ERCP.

\section{CONCLUSION}

Management of ERCP-related duodenal perforation remains controversial. CT and physical examination revealed no signs of peritonitis or retroperitoneal fluid collection in our case. In conclusion, conservative treatment would be success with careful radiographic and physical examination in these patients.

\section{REFERENCES}

[1] Lien, H.H., Huang, C.S., Shi, M.Y., Chen, D.F., Wang, N.Y., Tai, F.C., et al. (2004) Management of bile leakage after laparoscopic cholecystectomy based on etiological classification. Surgery Today, 34, 326-330. doi:10.1007/s00595-003-2712-2

[2] Binmoeller, K.F., Katon, R.M. and Shneidman, R. (1991) Endoscopic management of postoperative biliary leaks: Review of 77 cases and report of two cases with biloma formation. The American Journal of Gastroenterology, 86, 227-231.

[3] Christensen, M., Matzen, P., Schulze, S. and Rosenberg, J. (2004) Complications of ERCP: A prospective study. Gastrointestinal Endoscopy, 60, 721-731. doi:10.1016/S0016-5107(04)02169-8

[4] Enns, R., Eloubeidi, M.A., Mergener, K., Jowell, P.S., Branch, M.S., Pappas, T.M., et al. (2002) ERCP-related perforations: Risk factors and management. Endoscopy, 34, 293-298. doi:10.1055/s-2002-23650

[5] Pungpapong, S., Kongkam, P., Rerknimitr, R. and Kullavanijaya, P. (2005) Experience on endoscopic retrograde cholangiopancreatography at tertiary referral center in Thailand: Risks and complications. Journal of the Medical Association of Thailand, 88, 238-246.

[6] Kim, J., Lee, S.H., Paik, W.H., Song, B.J., Hwang, J.H., Ryu, J.K., et al. (2012) Clinical outcomes of patients who experienced perforation associated with endoscopic retrograde cholangiopancreatography. Surgical Endoscopy, 26, 3293-3300. doi:10.1007/s00464-012-2343-z

[7] Booth, F.V., Doerr, R.J., Khalafi, R.S., Luchette, F.A. and Flint, L.M. (1990) Surgical management of complications of endoscopic sphincterotomy with precut papillotomy. The American Journal of Surgery, 159, 132-135.

[8] Dubecz, A., Ottmann, J., Schweigert, M., Stadlhuber, R.J., Feith, M., Wiessner, V., et al. (20124) Management of ERCP-related small bowel perforations: The pivotal role of physical investigation. Canadian Journal of Surgery, 55, 99-104.

[9] Kim, B.S., Kim, I.G., Ryu, B.Y., Kim, J.H., Yoo, K.S., Baik, G.H. et al. (2011) Management of endoscopic retrograde cholangiopancreatography-related perforations. Journal of the Korean Surgical Society, 81, 195-204. doi:10.4174/jkss.2011.81.3.195

[10] Kayhan, B., Akdogan, M. and Sahin, B. (2004) ERCP subsequent to retroperitoneal perforation caused by endoscopic sphincterotomy. Gastrointestinal Endoscopy, 60, 833-835. doi:10.1016/S0016-5107(04)02171-6 